DOI: $10.5216 /$ racs.v5.63743

\title{
Escuela Intercultural Charrúa Itinerante (ESICHAI): estrategias de formación y capacitación interna del pueblo charrúa en Uruguay
}

\author{
Ana Maria Magalhães de Carvalho ${ }^{1}$
}

\section{RESUMEN}

Las narrativas que construyeron la nación uruguaya ocultaron los procesos de dominación y subordinación de los pueblos indígenas y los invisibilizaron. Dichas narrativas operan en relación a otros dispositivos, entre los que se encuentran los enunciados científicos y la educación hegemónica que, desde presupuestos evolucionistas y esencialistas, aprisionan a los indígenas en el pasado y niegan su existencia en el presente. Los procesos de reemergencia indígena en Uruguay, que tienen inicio en fines de los años ochenta, incluyen una profunda toma de conciencia por parte de los sujetos que se reconocen como charrúas o "descendientes" sobre la violencia de la que fueron víctimas sus ancestros y sobre la continuidad de esa violencia a través de dispositivos de invisibilización como la ciencia y la educación hegemónica. En este proceso se apropian, deconstruyen y reinterpretan dichos dispositivos para emprender acciones en concordancia con sus posicionamientos y objetivos políticos y transformar su realidad social. En el marco de una investigación realizada desde la antropología colaborativa, me propongo reflexionar sobre las acciones que desarrolla el Consejo de la Nación Charrúa (CONACHA) a partir de prácticas educativas decoloniales que involucran la educación intercultural. Me centraré en la Escuela Intercultural Charrúa Itinerante (ESICHAI) creada por los propios indígenas para enfrentar los discursos de invisibilización, recuperar la memoria colectiva y formar sus integrantes para que actúen en la lucha por el reconocimiento de sus derechos como pueblo existente y preexistente.

PALABRAS-CLAVE: Pueblo charrúa. Genocidio indígena. Estado nación uruguayo. Educación intercultural. Antropología colaborativa.

\section{Escola Intercultural Itinerante Charrúa (ESICHAI): estratégias de formação e capacitação interna do povo Charrúa no Uruguai}

\section{RESUMO}

As narrativas que construíram a nação uruguaia ocultaram os processos de dominação e subordinação dos povos indígenas e os invisibilizaram. Essas narrativas atuam em conjunto com outros dispositivos entre os quais se encontram os enunciados científicos e a educação hegemônica que, a partir de pressupostos evolucionistas e essencialistas, aprisionam os indígenas no passado e negam sua

\footnotetext{
${ }^{1}$ Facultad Latinoamericana de Ciencias Sociales (FLACSO), Cidade Autónoma de Buenos Aires, Argentina. Email: anamagbh@gmail.com.
}

Dossiê Redes de Inter-aprendizaje: nuevas cartografías interculturales y algunas propuestas de transformación 
existência no presente. Os processos de reemergência indígena, no Uruguai, que têm início no fim dos anos oitenta, incluem uma profunda tomada de consciência por parte dos sujeitos que se reconhecem como charruas ou "descendentes" sobre a violência de que foram vítimas seus antepassados e sobre a continuidade dessa violência através de dispositivos de invisibilização como a ciência e a educação hegemônica. Neste processo, se apropriam, desconstroem e reinterpretam esses dispositivos para empreender ações em concordância com seus posicionamentos e objetivos políticos e transformar sua realidade social. A partir de uma pesquisa realizada no âmbito da antropologia colaborativa, refletirei sobre as ações desenvolvidas pelo Conselho da Nação Charrua (CONACHA) utilizando práticas educativas decoloniais que incluem a educação intercultural. Para isso, me centrarei na Escola Intercultural Charrúa Itinerante (ESICHAI) criada pelos próprios indígenas para enfrentar os discursos de invisibilização, recuperar a memória coletiva e formar seus integrantes para que atuem na luta pelo reconhecimento dos seus direitos como povo existente e preexistente.

PALAVRAS-CHAVE: Povo charrúa. Genocídio indígena. Estado nação uruguaio. Educação intercultural. Antropologia colaborativa.

\section{Introducción: la construcción de Uruguay como un país "sin indios"}

Las narrativas hegemónicas que fundamentan la construcción de la nación uruguaya fueron efectivas en ocultar los procesos de dominación y subalternización de los indígenas e invisibilizarlos. Estas narrativas son legitimadas por diversos dispositivos, entre los que se encuentran los enunciados científicos y los discursos escolares. Dichos enunciados aprisionan a los indígenas en el pasado y niegan su existencia en el presente a través de presupuestos esencialistas y evolucionistas que afirman que en el Uruguay contemporáneo ya no hay indígenas, que en todo caso podría haber unos pocos "descendientes", pero que eso no los hace "indígenas verdaderos". Los discursos hegemónicos sostienen que los "descendientes" ya dejaron de ser indígenas, ya sea porque se mezclaron con los criollos o porque no practican las mismas tradiciones que sus ancestros. En el caso de Uruguay, como consecuencia de dichas narrativas, el Estado no reconoce los derechos colectivos de aquellos que hoy se autoadscriben como charrúas o "descendientes", y junto con Surinam y las Guyanas, es el único Estado de América del Sur que no ha ratificado el Convenio 169 de la Organización Internacional del Trabajo (OIT).

El pueblo charrúa habita los territorios que actualmente se encuentran bajo la soberanía de tres países: Argentina, Uruguay y Brasil. Las tolderías charrúas, especialmente en los años que antecedieron a la masacre de Salsipuedes —ocurrida en 1831 — nucleaban a personas de distintos orígenes, como los guenoas o minuanes, y también a afrodescendientes, que compartían la misma forma de vida y la organización social y política. Martín Delgado

Dossiê Redes de Inter-aprendizaje: nuevas cartografías interculturales y algunas propuestas de transformación

R. Articul.const.saber, 2020, v.5: e63743 
Cultelli (2018), charrúa de la comunidad Basquadé Inchalá, aclara que a fines del siglo XVIII, los charrúas y los guenoa-minuanes convivían y enfrentaban en conjunto a las autoridades coloniales. A este frente heterogéneo de resistencia se lo denominaba "charrúa".

Gustavo Verdesio, de origen uruguayo que se desempeña como profesor en la Universidad de Michigan (Estados Unidos), es uno de los pocos académicos que estudian el pasado indígena en Uruguay. En intertextualidad con Walter Mignolo (1989 apud Verdesio, 2012), reflexiona sobre la continuidad de los "legados coloniales" bajo distintas formas y retoma la categoría "colonialismo de colonos", acuñada por Lorenzo Veracini (2011 apud Verdesio, 2012), para reflexionar sobre las consecuencias de los procesos de colonización que se extendieron hasta 1830, cuando se establece el primer gobierno constitucional (1830-1834). De acuerdo con Lorenzo Veracini (2011 apud Verdesio, 2012), el tipo de colonialismo ocurrido en Uruguay, el colonialismo de colonos, tiene como característica el despojo territorial, el desplazamiento forzado de los indígenas y su asimilación o eliminación por medio de prácticas sistemáticas de exterminio. Ese tipo de colonialismo no intenta perpetuarse, sino que busca superarse y borrar sus huellas. En el caso de Uruguay, al imaginarse como una nación sin indígenas, la mayor parte de la población no percibe que hubo algún tipo de colonialismo. Las consecuencias negativas generadas por esos procesos, como la discriminación, la usurpación de tierras y la privación del derecho a su identidad, imponen obstáculos a los colectivos indígenas que actualmente luchan por su visibilización y derechos colectivos.

Tras la independencia, el Estado forjó narrativas nacionales que defendían y justificaban la eliminación de los indígenas; identificados como inferiores, salvajes y atrasados eran considerados un obstáculo para el proyecto civilizatorio de nación que se buscaba conformar. Para ello, organizó diversos ataques entre 1831 y 1834. Una de las matanzas más importantes fue la de Salsipuedes, que tuvo lugar el 11 de abril de 1831, al año siguiente de la consolidación de Uruguay como Estado nación (Arocena, 2013; Acosta y Lara, 1989). Las tropas del general Fructuoso Rivera emboscaron a los charrúas en el arroyo que lleva ese nombre, ubicado entre los departamentos de Paysandú y Tacuarembó, en el interior del país. Entre los muertos se encontraban guerreros, mujeres y niños. El territorio indígena fue entonces parcelado y repartido entre criollos y colonos europeos. Los sobrevivientes fueron igualmente repartidos como peones o sirvientes entre las familias pudientes, con el objetivo de que fueran educados y cristianizados; los niños fueron separados de sus madres y

Dossiê Redes de Inter-aprendizaje: nuevas cartografías interculturales y algunas propuestas de transformación R. Articul.const.saber, 2020, v.5: e63743 
las familias desmembradas en un claro intento de desarticularlas, desarmar el tejido comunitario e interrumpir la trasmisión de sus conocimientos y prácticas culturales (Olivera, 2014; Delgado Cultelli, 2014; Rodríguez y Michelena, 2018).

El Estado tiene un papel central en los dispositivos de invisibilización de los pueblos indígenas y el caso de Uruguay no es una excepción. Como plantea el historiador Ranajit Guha (2002), la elección de las narrativas que constituyen el discurso de la historia ocurre a partir de los valores dominantes del Estado. En este proceso algunas voces son silenciadas y por eso no pueden ser escuchadas. Al elegir lo que será considerado "histórico" el Estado no permite que los sujetos se conecten de maneras distintas con el pasado. Instituciones como la escuela y la familia son parte del aparado ideológico utilizado por el Estado para alcanzar sus propios fines, entre los cuales se encuentra la construcción de la nación y su hegemonía frente a otras formas de comunalización (Brow, 1990) que puedan existir en su interior. Balibar y Wallerstein (1991) también identifican una estrecha relación entre la formación nacional y el desarrollo de la escuela como institución que se presenta como base para la socialización de los individuos y la conformación de ciudadanos.

En la actualidad el Estado uruguayo aún mantiene una ideología dominante muy similar a la de la sociedad colonial y continúa haciendo uso de distintas herramientas para controlar, disciplinar y ocultar a los pueblos indígenas. La ideología del "último indio" es promovida por los aparatos de reproducción ideológica del Estado a través de diversos dispositivos, entre los cuales se encuentran la historiografía local y los enunciados científicos. La historiografía local, que conforma la educación oficial, ubica a los charrúas en el pasado y los representa de manera idealizada a partir de las imágenes prístinas construidas en las crónicas de la época colonial. Estas representaciones, todavía enseñadas en las escuelas, son funcionales al discurso de la extinción.

El silenciamiento por parte de los propios indígenas, a su vez, también fue funcional al discurso de la extinción y tuvo consecuencias que afectaron de distintas maneras la transmisión de sus prácticas culturales. El silenciamiento de los ancestros, como estrategia de supervivencia y resistencia, por miedo o por vergüenza, contribuyó a la invisibilización y generó interrupciones en los procesos de transmisión intergeneracional de las memorias que, en el mejor de los casos, quedaron alojadas en el ámbito doméstico perdiendo su sentido comunitario. Como consecuencia, los procesos de autoadscripción indígena sufrieron quiebres y muchas personas optaron por ocultar sus orígenes. En los diversos relatos que tuve la 
oportunidad de escuchar, los sujetos que hoy se reconocen charrúas o "descendientes" cuentan que ya de grandes empezaron a reflexionar sobre su identidad y a sentir algo distinto a los demás uruguayos. Pasan entonces a hacer investigaciones en los ámbitos familiares, primero de manera individual y después colectivamente, en búsqueda de esa memoria oral que, muchas veces, también fue transmitida por medio de acciones silenciosas. Recurrieron igualmente a la lectura de textos considerados clásicos de la antropología uruguaya y a las citas de documentos históricos y de crónicas, aunque consientes del sesgo con que fueron escritos. Esta procura por las voces silenciadas que revelan una historia alternativa a la oficial empieza a hacerse pública a partir de los años 90 del siglo $\mathrm{XX}$, generando reacciones negativas de parte del Estado, de la antropología uruguaya y de la sociedad general.

El presente trabajo es parte de la investigación que empecé a realizar en principios de 2015, en Uruguay, con el Consejo de la Nación Charrúa (CONACHA) ${ }^{2}$, en el marco de una etnografía colaborativa. Inspirada en los trabajos de Joanne Rappaport (2005, 2007, 2009, 2016), la investigación privilegió el trabajo de campo concebido como resultado de experiencias en las que se despliegan relaciones intersubjetivas y procesos de interpretación colectiva y la coteorización en concordancia con las pautas y objetivos políticos del pueblo charrúa. En esta instancia me propongo reflexionar sobre las estrategias que desarrolla el CONACHA a partir de prácticas educativas decoloniales, que involucran la educación intercultural, para enfrentar los discursos de invisibilización, recuperar la memoria colectiva y formar sus integrantes para que actúen en la lucha por su reconocimiento como pueblo existente y preexistente. Para ello me centraré en las acciones que desarrollan en el ámbito de la Escuela Intercultural Charrúa Itinerante (ESICHAI), creada en el año de 2017.

He organizado este artículo en tres apartados. En el primer apartado sintetizaré las experiencias previas que condujeron a la creación de la ESICHAI en el marco de los procesos de reemergencia indígena en Uruguay. En el segundo presentaré los objetivos de esta iniciativa y las principales actividades que llevaron a cabo hasta el presente. En el último

\footnotetext{
${ }^{2}$ Los colectivos conformados por personas que se reconocen charrúas y "descendentes" crearon el CONACHA en el año de 2005 impulsados por la necesidad de conformar un organismo a nivel nacional que tuviera mayor fuerza como interlocutor ante el Estado. Esta organización también tiene por objetivo recuperar memorias y prácticas ancestrales, generando sentidos de pertenencia entre quienes reconocen ancestros charrúas y favoreciendo los procesos de identificación y visibilización. Actualmente el CONACHA está integrado por cinco comunidades de distintos lugares del país: Basquadé Inchalá de Montevideo, Guyunusa de Tacuarembó, la Agrupación Queguay Charrúa (AQUECHA) de Paysandú, Betum de Salto y la Unión de Mujeres del Pueblo Charrúa (UMPCHA) conformada por las mujeres de todas las comunidades. La Asociación de Descendientes de la Nación Charrúa (ADENCH) se separó a comienzos del 2017, pero al igual que con Choñik — que nunca quiso pertenecer al CONACHA - mantienen buen diálogo y realizan algunas tareas conjuntas.
} 
apartado abordaré los resultados de las primeras evaluaciones realizadas por el CONACHA sobre la ESICHAI y presentaré algunas reflexiones y desafíos que enfrentan.

\section{1. "Somos charrúas. Un pueblo que sigue en pie.": los antecedentes de la ESICHAI}

A mediados de los años ochenta del siglo XX, y durante los años noventa, el movimiento indígena en América Latina se fortaleció. En el caso de Uruguay, el retorno a la democracia abrió espacio para los procesos de reemergencia indígena en el país. Sin embargo, ese "volver a aparecer" de un pueblo ya considerado extinto (Lazzari, 2017; Rodríguez, 2017; Verdesio, 2017) genera sorpresas y pone en cuestión los legados coloniales todavía vigentes en el país. La reemergencia de los charrúas confronta y resignifica el pasado colonial y los procesos de conformación del Estado nación uruguayo a partir de memorias subterráneas y resistentes, como propone el sociólogo Michael Pollak (1989), que entran en disputa con la memoria nacional y los dispositivos utilizados para su encuadramiento. Al proponer una visión crítica de la historia oficial y presentar una historia alternativa, la presencia actual de los indígenas amenaza las narrativas hegemónicas que cumplieron el objetivo de uniformizar a la nación. Si el problema indígena ya estaba resuelto, entonces ¿quiénes son esas personas que afloran en el espacio público afirmando que son charrúas y demandando derechos? Como reacción, el Estado y la ciencia refuerzan ideologías culturalistas de mediados del siglo XX, ahora amenazadas, para descalificar a los que se reconocen charrúas y "descendientes" y desarticular su accionar. En este contexto, importantes nombres de la antropología uruguaya como Renzo Pi Hugarte, fallecido en 2012, y Daniel Vidart, fallecido en 2019, y que además era asesor del ex presidente José Mujica, hicieron uso de expresiones como "charrumaníacos" (Montevideo Portal, 2010) o "charruístas" (Vidart, 2011) para despreciar a los colectivos indígenas actuales. Esta visión esencialista sobre los pueblos indígenas es todavía enseñada en la Facultad de Humanidades y Ciencias de la Educación de la Universidad de la República, que tampoco cuenta con líneas de investigación sobre los pueblos indígenas en el país.

Por otro lado, los procesos de reemergencia indígena en Uruguay incluyen una profunda toma de conciencia por parte de los sujetos que se reconocen como charrúas o "descendientes" sobre la violencia de la que fueron víctimas sus ancestros y sobre la continuidad de esa violencia a través de los dispositivos de invisibilización. Los colectivos

Dossiê Redes de Inter-aprendizaje: nuevas cartografías interculturales y algunas propuestas de transformación

R. Articul.const.saber, 2020, v.5: e63743 
organizados en el ámbito del CONACHA desarrollan estrategias internas con el objetivo de reconstruir el pueblo charrúa, contrarrestar los discursos sobre la extinción de los indígenas sancionados por la ciencia- y luchar por el reconocimiento de sus derechos colectivos. En este proceso se apropian, deconstruyen y reinterpretan dispositivos de invisibilización y de reproducción ideológica del Estado - entre los que se encuentran las narrativas hegemónicas, los enunciados científicos y la educación oficial - para emprender acciones en concordancia con sus posicionamientos y objetivos políticos y transformar su realidad social.

Desde hace varios años el CONACHA emprende distintas acciones para la reorganización del pueblo charrúa: realizan investigaciones de su memoria colectiva; dan clases, charlas y talleres para niños de escuelas rurales y urbanas; organizan encuentros y talleres colectivos; hacen viajes hacia el interior del país; y participan en encuentros nacionales e internacionales para mejorar su formación sobre los derechos de los pueblos indígenas. El aspecto formativo y pedagógico de esas actividades se nutre de los valores del pueblo charrúa, como la libertad, la horizontalidad y la palabra dada, y es pensado desde una perspectiva decolonial, es decir, como una reacción a la lógica opresiva y condenatoria de la colonialidad (Mignolo, 2005; Quijano, 1992). Ellos mismos, insertos en una sociedad que los invisibiliza, aprendieron a través de la educación oficial que los indígenas son primitivos y atrasados, tal como fueron descritos por los colonizadores, y que se extinguieron. Por otro lado, en las actividades formativas que organizan, deconstruyen los legados coloniales para dar lugar a procesos de identificación étnica anclados en el orgullo de ser indígena y de seguir resistiendo.

Durante el 2014, en el marco del proyecto Hacia la ratificación del convenio 169 de la OIT, el CONACHA realizó una serie de talleres sobre derechos e identidad indígena en varias ciudades del interior de Uruguay. Al año siguiente, organizaron tres grandes encuentros a los que llamaron "Encuentro de Saberes Ancestrales" (ESA) ${ }^{3}$, principal antecedente de lo que luego dio lugar a la ESICHAI. Estos encuentros se enfocaron en el diálogo colectivo, en la recreación conjunta de prácticas culturales y en actividades de formación de los miembros para el fortalecimiento de los procesos identitarios. También permitieron afianzar el contacto entre los colectivos urbanos y aquellos de las zonas rurales, una de las principales demandas de los colectivos indígenas y que también es uno de los objetivos del CONACHA.

\footnotetext{
${ }^{3}$ El primer Encuentro se realizó en febrero de 2015 en Remanso de Neptúnea (Canelones), el segundo en junio de 2015, en el marco del año nuevo indígena, en Valle Edén (Tacuarembó) y el tercero en diciembre de ese mismo año en Salto.
}

Dossiê Redes de Inter-aprendizaje: nuevas cartografías interculturales y algunas propuestas de transformación 
Los Encuentros están conformados por ceremonias, talleres, espacios de diálogo, intercambio de saberes, memorias y experiencias; además de espacios para la difusión de informes sobre actividades externas de las que participan, definición de acciones y proyectos conjuntos y la toma de decisiones consensuadas. En el primero ESA, Stella Vidal - de la Unión de Mujeres del Pueblo Charrúa (UMPCha) - dijo que por medio de los encuentros y demás actividades que organizan en conjunto están tratando de reconstruir las prácticas culturales, y explicó que reconstruir significa "juntar", en el sentido de "juntar las cosas del pasado para reconstruirlas en el presente". De este modo, "juntar" implica volver a visualizar las prácticas ancestrales para que cada uno las practique en la actualidad.

En dichos eventos los colectivos charrúas realizan ceremonias en las que recrean prácticas ancestrales, como por ejemplo prender el fuego sagrado, evocar a los ancestros con el sonido de las caracolas y las guampas, entonar palabras de agradecimiento al hacer circular el bastón de la palabra, y cantar y danzar canciones que ellos mismos compusieron en lengua charrúa, con palabras que recuperaron en sus investigaciones a través de publicaciones y documentos históricos.

Los talleres realizados en el marco de los Encuentros de Saberes Ancestrales son un elemento central de los procesos de fortalecimiento identitario. En un taller realizado en el monte de Valle Edén, Tacuarembó, durante el segundo ESA, Martín Delgado comentó que parte del empoderamiento de la identidad indígena es conocer qué usaban los antepasados, recrear las tradiciones, compartir las memorias orales y aprender sobre los derechos colectivos de los pueblos originarios.

En los tres ESA en los que participé los colectivos charrúas hicieron hincapié en la importancia de la educación para los pueblos indígenas, en particular para los niños y jóvenes. Acorde con estos intereses, realizaron talleres específicos sobre educación charrúa, compartieron experiencias realizadas en algunas escuelas e hicieron un taller de música destinada a los niños de una escuela de la región de Tacuarembó. Durante los talleres hablaron sobre las rupturas en la transmisión de las prácticas culturales después de la matanza de Salsipuedes y sus consecuencias, como tener que recurrir a las crónicas, a los archivos y a las memorias orales para recuperar las tradiciones que actualmente recrean, entre todos, por medio de esas actividades.

Guidaí Vargas, charrúa de la comunidad Basquadé Inchalá, y Blanca Rodríguez, educadora de la región de Tacuarembó, son maestras charrúas que llevaron reflexiones y 
prácticas educativas decoloniales a las escuelas donde actuaron. Guidaí aprovechó el 11 de abril, día de la matanza de Salsipuedes y actualmente fecha oficial en la que se celebra la nación charrúa y la identidad indígena en Uruguay, para enseñar sobre la violencia ejercida hacia el pueblo charrúa y su existencia en el presente. Incentivó a que los propios niños buscaran información en Internet y también en sus familias para discutir en clase. Varios de ellos se enteraron de que tenían antepasados indígenas y a partir de las memorias familiares que compartieron en la escuela reflexionaron sobre el mito acerca de la extinción de los charrúas.

En uno de los ESA Blanca Rodríguez habló de su experiencia y los cambios que lograron implementar en las escuelas donde trabaja. Llegaron a elaborar un programa de educación para niños charrúas con el objetivo de acercarlos al conocimiento de su pueblo, en el que incorporaron la enseñanza de valores, prácticas culturales, historia y lengua charrúa. También realizan pequeños cambios en las prácticas escolares cotidianas, como por ejemplo hacer círculos en lugar de filas y utilizar piedras y plantas del monte para las clases de ciencia. Con los cambios que vienen implementando, los niños ahora afirman que son charrúas en lugar de "descendientes". De este modo contribuyen a interrumpir la transmisión intergeneracional del miedo y la vergüenza, sentimientos que hicieron que sus familias se silenciaran sobre su identidad indígena.

En los últimos años, con el aumento de la visibilidad de sus demandas en el espacio público, los colectivos que conforman el CONACHA también sintieron la necesidad de desarrollar estrategias para la formación de sus integrantes, para que tengan pleno conocimiento de su historia y de los derechos de los pueblos indígenas. Impulsados por una convocatoria del Ministerio de Desarrollo Social de Uruguay para financiar acciones, proyectos o actividades socioculturales relacionadas con los derechos humanos, en el 2017 crearon la Escuela Intercultural Charrúa Itinerante (ESICHAI) con el objetivo de empoderar a las personas, de origen rural o urbano, que se reconocen como charrúas y como “descendientes" a través de la recuperación de la memoria colectiva y la formación de sus integrantes para la lucha por su reconocimiento y derechos. Esta iniciativa no solo conjuga los objetivos del CONACHA y sistematiza acciones anteriores en un proyecto educativo interno, sino que también propone una pedagogía y metodologías propias, considerando los distintos contextos y demandas de cada colectivo charrúa, y en contraposición a la educación oficial que sigue anclada en la ideología colonial.

Dossiê Redes de Inter-aprendizaje: nuevas cartografías interculturales y algunas propuestas de transformación R. Articul.const.saber, 2020, v.5: e63743 


\section{Escuela Intercultural Charrúa Itinerante: armando el gran quillapi ${ }^{4}$ de la memoria}

La Escuela Intercultural Charrúa Itinerante (ESICHAI) se enmarca entre las estrategias que desarrolla el CONACHA con el objetivo de fomentar prácticas desde lo que Catherine Walsh (2010) plantea como interculturalidad crítica. La interculturalidad entendida críticamente es un proyecto decolonial que pretende visibilizar y enfrentar lo que Quijano (2000) ha nombrado "colonialidad del poder" y que fijó una jerarquía racializada en la que los pueblos indígenas y afrodescendientes estarían en los niveles más bajos. Construida desde los sujetos históricamente subalternizados, la interculturalidad crítica es una herramienta y un proceso que apunta a transformar las estructuras sociales y epistémicas.

Uno de los principales retos con los que se enfrenta la ESICHAI es la coconstrucción de una pedagogía y metodología propias. La pedagogía que vienen construyendo, y que colectivamente llamaron "El gran quillapí de la memoria", es activa y horizontal, basada en la cosmovisión charrúa y apuntando al desarrollo del concepto de "buen vivir". Por esta razón, la metodología de la ESICHAI es principalmente vivencial, combinando la realización de talleres y espacios de reflexión, el intercambio de saberes y memorias entre las distintas personas, el diálogo intercultural, la investigación individual y colectiva y la construcción y sistematización colectiva del conocimiento.

Si bien los talleres de formación para el rescate y la revitalización de las prácticas y saberes ancestrales han sido una constante en los encuentros del CONACHA, como he comentado en el apartado anterior, la iniciativa de hacer algo más sistemático orientado a la formación de sus integrantes, para empoderarlos y darles herramientas para el activismo indígena, es algo nuevo. Mónica Michelena, de la comunidad Basquadé Inchalá, menciona que muchas veces son invitados por las escuelas para contar su historia, pero que son pocas las personas del CONACHA que se sienten lo suficientemente seguras para asistir. En una conversación que tuve con Martín Delgado, él agregó que,

Si bien es muy importante hablar desde el propio sentir y para eso uno no necesita gran instrucción educativa, también tenemos que considerar que en

\footnotetext{
${ }^{4}$ Capa confeccionad con cueros. Antiguamente las mujeres charrúas dibujaban parte de su memoria en el quillapí. Por eso, hoy, hacen uso de esta metáfora para representar el aporte de cada sujeto o comunidad a la reconstrucción de la memoria colectiva charrúa.
}

Dossiê Redes de Inter-aprendizaje: nuevas cartografías interculturales y algunas propuestas de transformación 
un debate público ese sentir no es suficiente. Es necesario cierto nivel de formación, de lo que es la historia y lo que son los derechos indígenas de acuerdo a las normativas internacionales. El promedio de las personas piensa que somos unos locos que nos ponemos la vincha y molestamos. Entonces hay que remar el doble para demostrar que no somos locos y que tenemos un pensamiento racional.

Los aspectos intercultural e itinerante de la ESICHAI buscan dar cuenta de las distintas memorias y trayectorias de personas y grupos que se autoadscriben como charrúas y "descendientes", incorporando los marcos espaciales y temporales que las conforman. La interculturalidad se basa en dos cuestiones principales: primeramente, las actividades promueven una instancia de diálogo reciproco de saberes entre personas que viven en distintos lugares de Uruguay y que tienen trayectorias y memorias diversas. En Montevideo, por un lado, trabajan con cuestiones más políticas, sobre la militancia, los derechos indígenas avalados por organismos internacionales e investigando sobre las crónicas y la historia en un sentido más formal. Las personas del interior, por otro lado, aportan más bien desde las trayectorias y vivencias personales, de los saberes que se transmiten a nivel familiar y desde la micropolítica. La interculturalidad también se ve reflejada en el puente que establecen entre el sistema epistémico occidental y el sistema ancestral propio del pueblo charrúa. De Occidente rescatan, entre otros aspectos, el sistema jurídico — ya que los derechos de los pueblos indígenas operan en el marco de los Estados nacionales_-, la historia — sobre la que profundizan leyendo documentos a contrapelo-, la antropología social y la arqueología que presentan investigaciones y conceptos que conforman los discursos y narrativas sobre los indígenas- y la biología y la zoología —que informan sobre las condiciones medioambientales de Uruguay. En los talleres, esos conocimientos son puestos en diálogo con los saberes propios; saberes que vienen desde la experiencia y la oralidad (Magalhães de Carvalho, 2018).

El formato itinerante de la ESICHAI — de acuerdo con el cual los talleres son realizados en distintas partes del país, donde está radicado cada colectivo- enriqueció el intercambio de experiencias entre los integrantes del CONACHA, en estrecha conexión con la interculturalidad. Esa experiencia permitió conocer las necesidades de cada comunidad para trabajar los temas y los talleres de formación desde sus propias demandas, desde lo que querían aprender según el contexto en que están insertos. También posibilitó romper con el centralismo de Montevideo, con la idea de que allí están "los que saben todo", al empoderar las personas del interior del país.

Dossiê Redes de Inter-aprendizaje: nuevas cartografías interculturales y algunas propuestas de transformación 
Quisiera brindar el ejemplo de uno de los primeros talleres que fue realizado y que según Nurimar Ceballos, charrúa de la comunidad Basquadé Inchalá y actual presidente del CONACHA, y Mónica Michelena, fue de los más provechosos. El taller sobre memoria, liderado por Martín Cultelli, fue realizado tanto en Montevideo como en Tacuarembó, interior del país. En el primer taller Martín recurrió a una metodología que le permitió territorializar las memorias, a partir de la proyección de un mapa de Uruguay, que estimuló reflexiones sobre los desplazamientos de los ancestros en distintos periodos de la historia. Cada persona decía de qué parte de Uruguay venía y Martín las ubicaba en el mapa. Se enteraron de que la mayoría de ellos venía de la región de la cuenca del Yi y del río Negro, y que empezaron a esparcirse alrededor de 1870. Esa fue la época de la construcción del ferrocarril y del alambrado en el campo, y es posible que esos hechos hayan generado procesos de despojo, explica Martín. La metodología de territorialización de las memorias, por lo tanto, permitió visualizar los lugares donde las trayectorias y memorias compartidas por cada participante fueron conformadas a lo largo del tiempo (Magalhães de Carvalho, 2018). La impresión de esas memorias en distintos puntos del mapa también los transformó en refugios de la memoria colectiva, en "lugares de memoria", como propone el historiador Pierre Nora (1993).

Dispuestas en forma circular, las personas que participaron en los talleres de memoria compartieron historias familiares que nunca habían contado antes, y aquellos que no contaban con mucha información, sintieron la motivación de indagar más. Mónica recuerda que hablaron de cuestiones familiares muy fuertes, que quizás en otro contexto no se hubieran sentido cómodas para contarlas. Salieron muchas historias de violencia transgeneracional, como violaciones y asesinatos, que los hicieron reflexionar sobre cómo la violencia del genocidio posiblemente se transformó en violencia doméstica. Martín también recuerda que un tema frecuente en los relatos compartidos fue la servidumbre; una violencia que se ejercía por medio de la explotación laboral. Nurimar agregó que muchas veces la identificación como indígena permanece escondida debido a la discriminación. En sus propias palabras: "El problema de no tener una identidad propia y quedar, así, flotando, es que nos queda ser el 'criadito'. Porque así sería yo si mi madre no se hubiera interpuesto. Te bautizaban y uno ya quedaba como su propiedad y te criaban como esclavo". Por eso, dice Martín, también era muy común que las familias indígenas dieran a los hijos a familias más pudientes, preferentemente blancas. Para él se trata de una forma de autoaceptación de la destrucción, que sería esa búsqueda por el blanqueamiento, y una de las peores manifestaciones del 
colonialismo, porque se trata de su incorporación y aceptación de la dominación (Magalhães de Carvalho, 2018).

El taller de memoria en Tacuarembó fue un poco distinto, explica Martín. Lo realizaron en conjunto con la comunidad Guyunusa. Si bien no utilizaron la metodología del mapa, también buscaron marcar los aspectos más relevantes para la memoria e historia de las personas de la región. Las principales cuestiones que salieron en el taller fueron los sitios sagrados y el racismo. En relación a la primera, los lugares más importantes presentes en las memorias se relacionaban a los espíritus de los ancestros. En los relatos hablaban de aspectos ontológicos, como las presencias o la energía de un cerro y también la existencia de los cerros-cementerios. Sobre el racismo, Martín cuenta que las personas de Tacuarembó sentían con más fuerza la dominación de los estancieros y relataban sus propias experiencias de discriminación, sobre cómo los miraban con desprecio, como si fueran inferiores. Algo que los diferenciaba de las personas de Montevideo es que en Tacuarembó no sentían que se negara la existencia de los charrúas, sino que eran tratados como inferiores (Magalhães de Carvalho, 2018).

El CONACHA pudo realizar una segunda versión de la ESICHAI en la segunda mitad de 2018 con el financiamiento de un proyecto que presentaron ante el Fondo para el Desarrollo de los Pueblos Indígenas de América Latina y El Caribe (FILAC). En la segunda versión tuvieron la oportunidad de hacer uso de la ESICHAI para prepararse colectivamente para reuniones con el gobierno de Uruguay y el Banco Mundial, ya que habían sido invitados por el Banco a participar de un proceso de consulta, como pueblos indígenas, para un proyecto sobre la emisión de gases de efecto invernadero. Los talleres sobre esta temática fueron dados por un miembro de Basquadé Inchalá y otro de la comunidad Guyunusa de Tacuarembó. Esas dos personas tuvieron la oportunidad de viajar a El Salvador para un curso de capacitación brindado por el Fondo Indígena en conjunto con el Banco Mundial. Entre todos definieron que aquellos que participen de cursos de formación afuera deben hacer una devolución interna en la ESICHAI. En el ámbito de los talleres pudieron armar una estrategia y una manera colectiva de presentarse y contestar las consultas del Banco. A lo largo de ese proceso reafirmaron la importancia de la formación en la ESICHAI para tener una agenda propia y prepararse para instancias de consulta, debates y reuniones con el Estado y otros organismos. También pudieron hacer lo mismo en relación a otros temas como los objetivos 
de desarrollo sostenible, biodiversidad, salud intercultural y alimentación hacia el buen vivir de los pueblos.

Otra novedad de la segunda versión de la ESICHAI fue la realización de un curso virtual. El curso consistió de dos módulos, cada uno con un mes de duración. Uno sobre identidad charrúa y el otro sobre memoria, ministrados por Mónica y Martín respectivamente. En conversaciones con ambos, me comentaron que se anotaron muchas personas del interior de Uruguay y también una charrúa de Entre Ríos, Argentina. Para los talleres hicieron uso de textos y videos y solicitaron que los participantes realizaran un trabajo final y participaran del foro de discusiones. Querían incentivar que las personas realizaran una pequeña investigación en el ámbito de las familias y que practicaran la escritura. La participación en el foro les pareció la parte más interesante y enriquecedora del curso, una vez que posibilitó que personas de distintas generaciones hicieran reflexiones e intercambiaran sus memorias familiares, generando insumos para armar el gran quillapí de la memoria.

El "volver a ser pueblo" por medio del accionar en el marco de la ESICHAI se desarrolla a partir de los encuentros y reencuentros de distintas trayectorias que conectan pasado y presente. Como plantea el antropólogo Tim Ingold (2011) la existencia humana se despliega a lo largo de caminos y rutas, en un constante movimiento. Los caminos trazados por las personas son trayectorias de vida en las que se tejen experiencias, historias y memorias. Las distintas trayectorias, a su vez, se encuentran y se entrelazan, conformando nodos o lugares de encuentros y de historias. Como cada persona es igualmente contenedora de las tradiciones y memorias repasadas por los ancestros, a la vez que las transmite, los lugares donde se entrelazan las distintas trayectorias también propician el encuentro con generaciones pasadas. En este sentido los talleres de memoria e identidad realizados en el ámbito de la ESICHAI buscaron compartir las trayectorias y evocar los recuerdos de cada persona o grupo en un proceso de recuperación de la memoria colectiva del pueblo charrúa. En este proceso, siguiendo al sociólogo Maurice Halbwachs (2006), el pasado es constantemente reconstruido, vivificado y resignificado de acuerdo con las necesidades del presente. La memoria es, por lo tanto, una herramienta y una práctica política que presenta un factor de transformación. Su recuperación, en conjunto con la formación de los miembros del CONACHA sobre los derechos indígenas, hace que la ESICHAI sea una estrategia fundamental en la lucha por el reconocimiento del pueblo charrúa en Uruguay. 


\section{La continuidad de la ESICHAI: evaluación y desafíos}

Los integrantes del CONACHA evalúan positivamente las actividades hasta ahora realizadas en la ESICHAI y se encuentran trabajando para ampliarla y dar continuidad al proyecto. Nurimar destaca como uno de los principales logros el hecho de que más personas empezaron a hacer investigación sobre su origen y memorias familiares y a autoreconocerse como indígenas. Ella recuerda que hace no mucho tiempo también decía que en Uruguay "no hay indios", ya que fue educada en el marco de la historia oficial que los niega y que sigue vigente. En el 2011 empezó a realizar los viajes a Salsipuedes ${ }^{5}$ y a tener más contacto con otras personas que se reconocían como indígenas y descendientes. Es así que conoce a los demás miembros de Basquadé Inchalá, pasa a frecuentar las reuniones e inicia el proceso de indagación sobre el pasado familiar, "porque antes no se hablaban de las cosas así en familia. No se decían cosas como tener un pariente que es indio. Había como un silencio", reflexiona.

Para su trabajo final del magisterio Guidaí eligió trabajar sobre cómo la escuela reproduce las narrativas nacionales acerca de un Uruguay "blanco" y homogéneo donde ya no hay presencia indígena. También hizo uso de ejemplos adquiridos a través de su propia experiencia como maestra para proponer un modelo de escuela alternativo. En una conversación que tuvimos Guidaí manifestó lo siguiente,

Llevó tiempo universalizar la escuela a partir de una ideología que privilegia la ciencia y la razón, y que defiende la supremacía del blanco europeo, pero se logró. Por eso, hoy, muchos de nosotros, los indígenas, creemos lo que nos contaron en la escuela acerca de nuestros antepasados, o que no existimos.

Guidaí también agrega que los libros escolares todavía utilizan las crónicas para reproducir la visión de los colonizadores sobre la de los indígenas, una visión en la que estos últimos son descriptos como feroces, primitivos y atrasados. "La educación siempre está sometida al poder político, entonces es necesario cambiar la sociedad, pero también la universidad, que es la que forma a la gente", concluye.

A partir de conversaciones con miembros del CONACHA, me gustaría presentar algunas de sus principales reflexiones sobre la experiencia con la ESICHAI. En primer lugar, con los talleres que realizaron hasta ahora notaron que los participantes, y en especial los

\footnotetext{
${ }^{5}$ Desde 1997 los colectivos charrúas realizan viajes a Salsipuedes el 11 de abril para rendir homenaje a los ancestros.
}

Dossiê Redes de Inter-aprendizaje: nuevas cartografías interculturales y algunas propuestas de transformación

R. Articul.const.saber, 2020, v.5: e63743 
jóvenes, están más preparados, involucrados y comprometidos. Pese a los logros alcanzados, Mónica cree que a los jóvenes todavía les falta adquirir mayores conocimientos sobre la historia del pueblo charrúa y del CONACHA. En el marco de la ESICHAI tienen planeado realizar encuentros específicos con el objetivo de empoderarlos y ampliar su participación en los espacios de decisión. Martín explica que nunca hicieron un encuentro de jóvenes en el ámbito de la organización y cree que con los encuentros respaldados por la ESICHAI los jóvenes charrúas de distintos lugares de Uruguay tendrán la oportunidad de reunirse y formarse también en relación a la agenda internacional de jóvenes indígenas.

En segundo lugar, consideran que la incorporación del curso virtual fue algo muy exitoso. Este tipo de modalidad permitió que más personas pudieran participar y compartir sus memorias y trayectorias en los foros de discusión. No obstante, con esos cursos se dieron cuenta de la dificultad que muchos participantes tenían para leer y entender los textos y también para escribir. Un objetivo y también desafío que tienen con la ESICHAI es incentivar el hábito de lectura y la escritura. Para Martín aunque la oralidad sea muy propia de los pueblos indígenas, para la academia, el Estado y otras organizaciones con las que tienen que interactuar la escritura es fundamental, y es importante que la sepan manejar. Entender un texto, reflexionar sobre las lecturas y aprender a escribir empodera y genera autonomía para que todos estén preparados para luchar por el reconocimiento de la existencia del pueblo charrúa y sus derechos colectivos. Internamente también pueden hacer uso de la lectura y la escritura, desde la cosmovisión charrúa y a su manera, para sistematizar su historia y memorias. En concordancia con este objetivo, también esperan, a futuro, contar con una instancia de formación más amplia y procesual, con cursos más extensos en cada localidad, para que los distintos colectivos puedan avanzar en sus investigaciones locales, registrarlas a través de textos, audios o videos, reflexionar sobre formas alternativas de transmisión de la memoria y de las prácticas culturales, y teorizar desde su propia cosmovisión, logrando hacer su propia etnografía.

Uno de los desafíos que enfrenta el CONACHA en el desarrollo de la metodología de la ESICHAI es la incorporación de la etnografía. Al considerar los objetivos políticos de los colectivos charrúas, la etnografía colaborativa que antropólogos y antropólogas y estudiantes de antropología venimos realizando con el CONACHA también tiene como propósito contribuir a que los propios indígenas hagan uso de técnicas etnográficas para recuperar los fragmentos de su memoria colectiva. La apropiación nativa de la producción etnográfica tiene

Dossiê Redes de Inter-aprendizaje: nuevas cartografías interculturales y algunas propuestas de transformación R. Articul.const.saber, 2020, v.5: e63743 
una razón distinta, sostiene Alcida Ramos (2007); su interés en la autorrepresentación es más político que académico, lo que hace que la observación y los análisis sean distintos a los de las etnografías clásicas, ya sea en la elección de tópicos, en el estilo o en relación al público. Las autoetnografías también parecen dirigirse a la instrumentalización de los recursos étnicos que serán aplicados en contextos de política interétnica. La apropiación de herramientas de la antropología por los propios indígenas, entre las que se destaca la etnografía, posibilita que sean agentes plenos, productores de conocimiento antropológico y que tomen las riendas del curso de su historia.

La posibilidad de llevar a cabo la metodología vivencial en forma procesual y a largo plazo también se encuentra con otro obstáculo: las exigencias y plazos de los organismos externos. El período que tienen para realizar las actividades suele ser muy corto, por lo que también quieren buscar formas de autogestión con fondos propios. Para Mónica el hecho de que el CONACHA haya realizado diversas experiencias anteriores a la ESICHAI por cuenta propia muestra que la autogestión es algo que puede funcionar. La idea es dar la oportunidad a un proceso cocreativo en que todos participen, aporten y decidan cómo quieren seguir.

Como he mostrado en este trabajo, la ESICHAI también tiene como eje la formación de sus miembros en cuestión de derechos indígenas. El propósito central es que todos conozcan sus derechos como pueblo existente y preexistente y que puedan hacer frente al Estado, la academia y la sociedad general, y participar de reuniones y encuentros nacionales e internacionales. En este marco, también tienen como desafío profundizar los temas relativos al Convenio 169 de la OIT en el ámbito de la ESICHAI y empezar a elaborar estrategias hacia la ratificación del Convenio por el Estado uruguayo.

Finalmente, diversos representantes del CONACHA suelen ser invitados a dar charlas y clases en escuelas. Hasta ahora lo vienen haciendo cada uno por su cuenta, a su manera. Tienen por objetivo sistematizar esas actividades en la ESICHAI, es decir, dar los talleres y cursos para charrúas y también no charrúas y enmarcar este aporte a la sociedad en el ámbito de la Escuela. Con eso lograrían fortalecer y profundizar su aspecto intercultural. Para lograr este objetivo será necesario que todos manejen la misma pedagogía, una pedagogía que vienen construyendo colectivamente, entre todos. Uno de los obstáculos que se interpone a este objetivo es la falta de apoyo del Estado, que aún no los reconoce como indígenas. Como reflexiona Guidaí, para que la educación en el país sea intercultural es necesario cambiar los cimientos, las estructuras que siguen reproduciendo situaciones de desigualdad e injusticia.

Dossiê Redes de Inter-aprendizaje: nuevas cartografías interculturales y algunas propuestas de transformación R. Articul.const.saber, 2020, v.5: e63743 
Iniciativas como la ESICHAI pueden generar un impacto y contribuir al cambio, pero de a poco. Cambiar las estructuras es un paso fundamental hacia la educación intercultural, hacia un conocimiento que se dé a partir del aporte de todos y que incluya la diversidad existente en el ámbito de un Uruguay que todavía se cree homogéneo y "sin indios”.

\section{Palabras finales}

Los discursos que sostienen y legitiman las narrativas hegemónicas en Uruguay fueron construidos por las elites políticas intelectuales del siglo XIX con el objetivo de excluir a los sujetos no europeos y sus aportes a la construcción del Estado nación uruguayo. Los indígenas eran considerados bárbaros y primitivos, por lo que no se adecuaban a los ideales de progreso, civilización y a la noción de propiedad privada que deberían conformar la nueva república. Distintos dispositivos, entre los cuales están los enunciados científicos de disciplinas como la historia y la antropología, y la educación oficial contribuyeron a legitimar la invisibilización de los indígenas en la memoria nacional. Como plantea Pollak (1989), esta memoria colectiva, enmarcada como memoria nacional, tiene un carácter homogeneizante y opresor de todo aquello que no se quiere contar como historia oficial. En este proceso se instaura de manera central la supremacía de la razón en la búsqueda del conocimiento y en los aprendizajes a la vez que otros saberes, relatos y conocimientos son inferiorizados y subalternizados.

Los presupuestos esencialistas, que respaldan los discursos de invisibilización de los indígenas en Uruguay, siguen vigentes en la antropología uruguaya y también en la educación hegemónica. Como consecuencia las personas que hoy se reconocen como charrúas y "descendientes" son descalificadas y llamadas de "indios truchos". Esta visión esencialista, en la que los diacríticos tienen lugar destacado, llegó a tener fuerza también en el seno del movimiento indígena. Martín y Mónica explican que antes sentían la necesidad de ponerse el quillapí y la vincha cuando hacían alguna aparición en el espacio público, ya que suponían que era lo que exigía la sociedad para que los consideraran indígenas; es decir, suponían que debían presentarse de un modo semejante a como figuran en los libros de historia. También sentían la exigencia de hablar de las crónicas, que es de donde se extrae el saber autorizado sobre su historia, mientras la memoria oral estaría vinculada a los mitos y creencias mágicoreligiosas. Sin embargo, en los últimos años, atravesaron un proceso de revalorización de sí

Dossiê Redes de Inter-aprendizaje: nuevas cartografías interculturales y algunas propuestas de transformación R. Articul.const.saber, 2020, v.5: e63743 
mismos y comprendieron que ellos son charrúas del presente, no del siglo XVIII. También pasaron por un proceso de autoreflexión y toma de conciencia respecto a la supervivencia de las memorias orales, a pesar de los efectos de los procesos de invisibilización y del silencio de sus ancestros. Como sostiene Halbwachs (2006), la memoria es esencialmente colectiva y la presencia del grupo es necesaria para recordar, por lo que las estrategias de reorganización del pueblo charrúa están ligadas a la reconstituición de esa memoria colectiva que buscan recuperar como si fuera una suerte de rompecabezas que se empeñan en rearmar.

La Escuela Intercultural Charrúa Itinerante reúne y sistematiza las diversas acciones que los colectivos charrúas realizan para reorganizarse como pueblo. También responde a una demanda de los maestros y educadores que actúan en escuelas rurales y urbanas, y de las organizaciones y comunidades que conforman el CONACHA, especialmente aquellas del interior de Uruguay. El aumento de la visibilidad del Consejo de la Nación Charrúa a través de su participación en el espacio público y en las oficinas gubernamentales en las que se toman decisiones también produjo otra demanda interna: generar instancias de formación y capacitación de nuevos líderes para que más personas estén preparadas para pararse ante el Estado y la academia y luchar por el reconocimiento de sus derechos colectivos.

Los aspectos intercultural e itinerante de la ESICHAI reflejan la diversidad de memorias y trayectorias que aporta cada uno de los colectivos que conforman el CONACHA, a la que se suma también las demás personas que se reconocen como charrúas y “descendientes" pero que no integran esta organización. La coconstrucción de una pedagogía y metodología propias apuntan al intercambio de saberes, a la construcción colectiva de conocimiento, al empoderamiento de nuevos líderes y a la definición conjunta de lo que es el "buen vivir" para el pueblo charrúa. En este espacio se reúnen para forjar una historia alternativa a la oficial, una contrahistoria que contrarresta los discursos de la extinción y los enunciados científicos esencialistas. La ESICHAI es una instancia formativa transformadora que cuestiona los legados coloniales (Mignolo, 1989), que todavía se presentan como el principal obstáculo para el reconocimiento oficial del pueblo charrúa y de sus derechos colectivos.

La creación de la ESICHAI es reciente, pero sus principales resultados son positivos. Lo que aprendieron hasta ahora sirve de motor para elaborar nuevas propuestas que posibiliten al pueblo charrúa alcanzar sus objetivos. La experiencia también les irá permitiendo profundizar la pedagogía a la que refieren como "El gran quillapí de la memoria"

Dossiê Redes de Inter-aprendizaje: nuevas cartografías interculturales y algunas propuestas de transformación R. Articul.const.saber, 2020, v.5: e63743 
y afinar la realización de los cursos internos y su ampliación hacia la sociedad general. En este proceso tienen un importante desafío: la interculturalidad en tanto proyecto político, social y epistémico no implica incorporar lo diferente a las estructuras actuales sino que hacer frente a las jerarquías que siguen reproduciendo situaciones de desigualdad e injusticia y transformarlas desde una perspectiva decolonial (Walsh, 2010). Por lo tanto, aunque emerja desde los sujetos subalternizados, la interculturalidad debe involucrar a todos los sectores de la sociedad.

\section{Referencias bibliográficas}

ACOSTA Y LARA, Eduardo. La guerra de los charrúas: período patrio I y II. Montevideo: Librería Linardi y Risso 1989.

AROCENA, Felipe. Uruguay: un país más diverso que su imaginación. Una interpretación a partir del censo de 2011. Revista de Ciencias Sociales 26 (33):137-158, 2013.

BALIBAR, Étienne; WALLERSTEIN, Immanuel. La forma nación: historia e ideología En Raza, nación y clase, Pp. 135-167. Madrid: IEPALA, 1991.

BROW, James. Notes on Community, Hegemony, and uses of the past. Anthropological Quarterly, 63 (1):1-6, 1990.

DELGADO CULTELLI, Martín. La reemergencia Indígena en el Uruguay: el caso de la Nación Charrúa. Mate Amargo Digital. La ronda del mate $n^{\circ} 21$. Publicación mensual del MLN-Tupamaros, 2014. Disponible en: http://www.mateamargo.org.uy/2014/09/26/lareemergencia-indigena-en-el-uruguay-el-caso-de-la-nacion-charrua/. Acceso 12 de abril, 2020.

Denominaciones Indígenas en la Banda Oriental: una discusión abierta. Zur, pueblos y voces, 2018. Disponible en: http://zur.org.uy/content/denominaciones-ind\%C3\%ADgenasen-la-banda-oriental-una-discusi\%C3\%B3n-abierta. Acceso 12 de abril, 2020.

GUHA, Ranajit. Las Voces de La Historia y Otros Estudios Subalternos. Barcelona, Crítica, 2002.

HALBWACHS, Maurice. A memória coletiva. São Paulo: Centauro, 2006.

INGOLD, Tim. Being Alive. Essays on Movement, Knowledge and Description. London y New York: Routledge, 2011.

LAZZARI, Axel. ¿Por qué el término reemergencia indígena?: Acentuando dis-continuidades y re-emergencias. Reemergencia indígena en los países del Plata: Los casos de Uruguay y de Argentina. Conversaciones del Cono Sur 3(1), 43-50, 2017. Disponible en:

Dossiê Redes de Inter-aprendizaje: nuevas cartografías interculturales y algunas propuestas de transformación 
https://conosurconversaciones.wordpress.com/volumen-3-numero-1/. Acceso 12 de abril, 2020.

MAGAlHAES DE CARVALHO, Ana Maria. Procesos de reemergencia indígena en Uruguay: Reflexiones sobre las estrategias del pueblo charrúa frente a los discursos de invisibilización. Tese (Magíster en Antropología Social) - Facultad Latinoamericana de Ciencias Sociales, Buenos Aires: FLACSO Argentina, 2018.

MIGNOLO, Walter. La opción des-colonial, desprendimiento y apertura: un manifiesto. Tabula Rasa, 8: 243-281, 2005.

MONTEVIDEO PORTAL. Tabaré, That`s Right: Renzo Pi Hugarte y los charrúas. 26 de febrero de 2010. Disponible en: https://www.montevideo.com.uy/Tiempo-libre/Renzo-PiHugarte-y-los-charruas-uc104044. Acceso 12 de abril, 2020.

NORA, Pierre. Entre memória e história: a problemática dos lugares. Projeto História. São Paulo: PUC-SP. 10:7-28, 1993.

OLIVERA, Andrea. Etnografía decolonial con colectivos charrúas: reflexionando sobre interconocimientos. Anuario Antropología Social y Cultural en Uruguay 12:139-153, 2014.

POLLAK, Michael. Memória, Esquecimento, Silencio. Estudos Históricos 2 (3), 3-15, 1989. Disponible en: http://bibliotecadigital.fgv.br/ojs/index.php/reh/article/view/2278/1417. Acceso 12 de abril, 2020.

QUIJANO, Anibal. Colonialidad y Modernidad/Racionalidad, En Los Conquistados: 1492 y la población indígena de las Américas. H. Bonilla, comp. p. 437-449. Quito: FLACSO / Ediciones Libri Mundi, 1992.

Colonialidad del Poder, Eurocentrismo y América Latina. En E.Lander (Comp). La colonialidad del saber. Buenos Aires: CLACSO, 2000.

RAMOS, Alcida Rita. Do engajamento ao desprendimento. Campos 8 (1):11-32, 2007. Disponible en: file:///C:/Users/FCEN/Downloads/9559-29377-1-PB\%20(1).pdf. Acceso 12 de abril, 2020.

RAPPAPORT, Joanne; RAMOS PACHO, Abelardo. Una historia colaborativa: retos para el diálogo indígena- académico. Historia Crítica, 29:39-62, 2005. Disponible em: http://www.redalyc.org/articulo.oa?id=81102902. Acceso 12 de abril, 2020.

Más allá de la escritura: la epistemología de la etnografía en colaboración. Revista Colombiana de Antropología 43: 197-22, 2007. Disponible en: http://www.redalyc.org/articulo.oa?id=105015277007. Acceso 12 de abril, 2020.

Rethinking the Meaning of Research in Collaborative Relationships. Collaborative Anthropologies 9 (1):1-31, 2016. 
Utopías interculturales. Intelectuales públicos, experimentos con la cultura y pluralismo étnico en Colombia. Bogotá: Universidad del Rosario, 2009.

RODRÍGUEZ, Mariela Eva. Reemergencia indígena en los países del Plata: Los casos de Uruguay y de Argentina. Reemergencia indígena en los países del Plata: Los casos de Uruguay y de Argentina. Conversaciones del Cono Sur 3(1):1-7, 2017. Disponible en: https://conosurconversaciones.wordpress.com/volumen-3-numero-1/. Acceso 12 de abril, 2020.

RODRÍGUEZ, Mariela Eva; MICHELENA, Mónica. El gran quillapí de la memoria. Reflexiones sobre la ideología de blanqueamiento y la reemergencia indígena en los países del Plata desde una investigación colaborativa. Dossier Memórias Indígenas: silêncios, esquecimentos, impunidade e reivindicação de direitos e acesso à justiça, Ricardo Verdum y Ana Margarita Ramos, eds. Revista Abya Yala, 2018.

VERDESIO, Gustavo. Colonialismo acá y allá: Reflexiones sobre la teoría y la práctica de los estudios coloniales a través de fronteras culturales. Cuadernos del CILHA 13 (17):175-191, 2012.

Comentarios sobre la mesa "Reemergencia indígena en los países del Plata: el caso de Argentina. Reemergencia indígena en los países del Plata: Los casos de Uruguay y de Argentina. Conversaciones del Cono Sur 3 (1):77-83, 2017. Disponible en: https://conosurconversaciones.wordpress.com/volumen-3-numero-1/. Acceso $12 \mathrm{de}$ abril, 2020.

VIDART, Daniel. El regreso del mito charruísta, 2011. Disponible en; http://profelagrotta.blogspot.com/2011/04/el-regreso-del-mito-charruista-por.html. Acceso 12 de abril, 2020.

WALSH, Catherine. Interculturalidad crítica y educación intercultural". Construyendo Interculturalidad Critica, J. Viaña, L. Tapia, C.Walsh, La Paz: Convenio Andrés Bello. ISBN: 978- 99954-785-1-3, 2010.

Submetido em 02 de junho de 2020.

Aceito em 03 de novembro de 2020.

Publicado em 10 de novembro de 2020. 